\title{
Exploring spatial variations and factors associated with childhood stunting in Ethiopia: spatial and multilevel analysis
}

\author{
Demewoz Haile ${ }^{1}$, Muluken Azage ${ }^{* *}$, Tegegn Mola ${ }^{2}$ and Rochelle Rainey ${ }^{3}$
}

\begin{abstract}
Background: Stunting reflects a failure to receive adequate nutrition over a long period of time. Stunting is associated with adverse functional consequences including poor cognition, low educational performance, low adult wages, and poor reproductive outcomes. The objective of the study was to investigate spatial variations and factors associated with childhood stunting in Ethiopia.
\end{abstract}

Methods: This study is a secondary data analysis of the 2011 Ethiopian Demographic and Health Survey (EDHS). A total of 9893 children aged 0-59 months were included in the analysis. The Getis-Ord spatial statistical tool was used to identify high and low hotspots areas of stunting. A multilevel multivariable logistic regression was used to identify factors associated with stunting.

Results: Statistically significant hotspots of stunting were found in northern parts of the country whereas low hotspots where there was less stunting than expected were found in the central, eastern, and western parts of the country. In the final model of multilevel logistic regression analysis, individual and community level factors accounted for $36.6 \%$ of childhood stunting. Short birth interval [AOR $=1.68 ; 95 \% \mathrm{Cl}$ : $(1.46-1.93)]$, being male $[A O R=1.20 ; 95 \% \mathrm{Cl}:(1.08-1.33)]$, and being from a male-headed household [AOR $=1.18 ; 95 \% \mathrm{Cl}:(1.01-1.38)]$ were the factors that increased the odds of stunting at the individual level. Children in the age group between 24-35 months were more likely to be stunted than children whose age was less than one year [AOR $=6.61 ; 95 \% \mathrm{Cl}$ : (5.17-8.44)]. The odds of stunting among children with severe anemia were higher than children with no anemia $[A O R=3.23 ; 95 \% \mathrm{Cl}:(2.35-4.43)]$. Children with mothers who had completed higher education had lower odds of being stunted compared to children whose mothers had no formal education [AOR $=0.42 ; 95 \% \mathrm{Cl}$ : $(0.18-0.94)]$. The odds of being stunted were lower among children whose fathers completed higher education $[\mathrm{AOR}=0.58 ; 95 \% \mathrm{Cl}$ : (0.38-0.89)] compared to children whose fathers had no formal education. Children whose mothers who had high a Body Mass Index (BMI) $\left(\geq 25.0 \mathrm{~kg} / \mathrm{m}^{2}\right)$ were less likely to be stunted compared with children whose mothers had a normal BMI $\left(18.5 \mathrm{~kg} / \mathrm{m}^{2}-24.9 \mathrm{~kg} / \mathrm{m}^{2}\right)[\mathrm{AOR}=0.69 ; 95 \% \mathrm{Cl}:(0.52-0.90)]$. Children from the poorest wealth quintile had higher odds of being stunted compared to children from the richest wealth quintiles [AOR $=1.43 ; 95 \% \mathrm{Cl}:(1.08-1.88)]$. Unavailability of improved latrine facilities and living in the northern parts of the country (Tigray, Affar, Amhara and Benishangul-Gumuzregions) were factors associated with higher odds of stunting from the community-level factors.

Conclusion: Stunting in children under five years old is not random in Ethiopia, with hotspots of higher stunting in the northern part of Ethiopia. Both individual and community-level factors were significant determinants of childhood stunting. The regions with high hotspots of child stunting should be targeted with additional resources, and the identified factors should be considered for nutritional interventions.

Keywords: Stunting, Children, Ethiopia

\footnotetext{
* Correspondence: mulukenag@yahoo.com

'Department of Public Health, College of Medicine and Health Sciences,

Bahir Dar University, P.O. Box 79, Bahir Dar, Ethiopia

Full list of author information is available at the end of the article
} 


\section{Background}

Height-for-age Z-score is used as an indicator of linear growth retardation and cumulative growth deficits in children [1]. Stunting is defined as a child with a heightfor-age Z-score (HAZ) less than minus two standard deviations (<-2 SD) below the median of a reference height-for-age standard. Stunting reflects a failure to receive adequate nutrition over a long period of time, and is affected by both recurrent and chronic illness [2]. Stunting in childhood is associated with adverse functional consequences later in life including poor cognition, poor educational performance, low adult wages and poor reproductive outcomes [3, 4]. Stunted children also have a higher risk of being overweight or obese later in life, putting them at risk of chronic disease in adulthood [3, 5-7].

Childhood stunting varies not only across various regions of the world but also within and between local authorities, regional space dimensions and/or countries [8]. Although Ethiopia has made steady progress in reducing stunting (from 2000-2011 stunting declined from $58 \%$ to $44 \%)[9,10]$, the prevalence of stunting is still one of the highest in the world [10], and the issue is a national priority. In order to accelerate efforts in reducing stunting, along with other nutritional problems, Ethiopia revised its national nutrition program in 2013 [11]. Identifying hotspots, or areas where the prevalence of stunting is higher than the national average, would help the Ethiopian Government strategically intensify interventions in order to reduce the prevalenceof stunting in the country.

There aremany studies which determine the prevalence of stunting and analyze socioeconomic, demographic and cultural factors associated with childhood stunting in Ethiopia [12, 13]. However, no spatial analysis has identified the hotspotsof stunting in the country. Moreover, many of the previous studies used standard logistic regression to identify the independent predictors of stunting. Analyzing variables from different levels at one single common level using the standard binary logistic regression model leads to biased results (loss of power or Type I error). Households in the same geographic cluster have common characteristics such as seasonal variability, types of crops and housing which can have a similar impact on the nutritional status of children in the cluster. The assumptions of independence among individuals within the same cluster and of equal variance across clusters are violated in the case of grouped data. Hence, a multilevel analysis is the appropriate statistical analysis method for such a study. This study employed a multilevel logistic regression analysis which has a number of advantages over standard logistic regression, as described in detail by Guo and Zhao [14]. This study aimed to investigate the spatial variation of stunting and the factors associated with stunting in Ethiopia using spatial and multilevel analyses.

\section{Methods \\ Study design and setting}

An in-depth secondary data analysis was conducted using Ethiopian Demographic and Health Survey (EDHS) data from 2011. The EDHS is carried out every five years to provide health and health-related indicators at the national and regional levels in Ethiopia. Administratively, regions in Ethiopia are divided into zones, and zones, into administrative units called woredas. Each woreda is further subdivided into the lowest administrative unit, called kebeles. During the 2007 census each kebele was subdivided into census enumeration areas (EAs), which were convenient for the implementation of the census. The 2011 EDHS sample was selected using a stratified, twostage cluster design where EAs were the sampling units for the first stage, and households for the second stage. The detailed sampling procedure is presented in the full EDHS report [10].

\section{Measurement}

The length of children aged $<24$ months was measured during the EDHS in a recumbent position to the nearest $0.1 \mathrm{~cm}$ using a locally made board with an upright wooden base and movable headpieces. Children $\geq 24$ months were measured while standing upright. The height-for-age Zscore, an indicator of nutritional status, was compared with reference data from the WHO Multicentre Growth Reference Study Group, 2006 [15]. Children whose height-for-age Z-score is $<-2 \mathrm{SD}$ from the median of the WHO reference population are considered stunted (short for their age). A wealth index was constructed using principal components analysis on household asset data to categorize individuals into five wealth quintiles (poorest, poorer, medium, richer and richest). Variables included in the wealth index were ownership of selected household assets, size of agricultural land, quantity of livestock and materials used for house construction [16]. Three steps were used in the construction of the wealth index to permit greater adaptability of the wealth index to both urban and rural areas. In the first step, a subset of indicators common to urban and rural areas was used to create wealth scores for households in both areas. In the second step, separate factor scores were produced for households in urban and rural areas using area-specific indicators. The third step combined the separate area-specific factor scores to produce a nationally-applicable combined wealth index by adjusting area-specific scores through a regression on the common factor scores. A more detailed description of the wealth index is presented in the full EDHS report [10]. 


\section{Explanatory variables}

The individual- and community-level variables included in the study as explanatory variables are shown in Table 1, along with the coding and definitions. Individual-level variables include socio-demographic and economic

Table 1 Variables definition

\begin{tabular}{|c|c|}
\hline \multicolumn{2}{|c|}{ Individual-level factors } \\
\hline \multicolumn{2}{|l|}{ Child factors } \\
\hline $\begin{array}{l}\text { Age of child } \\
\text { (months) }\end{array}$ & $\begin{array}{l}\text { Categorized into (1) 0-11; (2) 12-23; (3) 24-35; } \\
\text { (4) 36-47; and (5) 48-59. }\end{array}$ \\
\hline Sex of child & Categorized into (1) female and (2) male. \\
\hline Birth weight (g) & $\begin{array}{l}\text { Categorized into (1) low }<2500 \text { and (2) } \\
\text { normal } \geq 2500 \text {. }\end{array}$ \\
\hline Type of birth & $\begin{array}{l}\text { Categorized into (1) single and (2) multiple } \\
\text { birth }\end{array}$ \\
\hline Immunization & $\begin{array}{l}\text { Categorized into (1) incomplete or (2) } \\
\text { complete }\end{array}$ \\
\hline Anemia & $\begin{array}{l}\text { Categorized into (1) non-anemic; (2) mild; (3) } \\
\text { moderate; (4) sever }\end{array}$ \\
\hline
\end{tabular}

Maternal/household

factors

$\begin{array}{ll}\text { Maternal age in years } & \text { Categorized into (1) 15-24; (2) 25-34; or } \\ & \text { (3) 35-49. } \\ \begin{array}{l}\text { Educational level of } \\ \text { mother }\end{array} & \begin{array}{l}\text { Categorized into (1) no formal education; (2) } \\ \text { primary; (3) secondary; or (4) higher. }\end{array} \\ \begin{array}{l}\text { Mother's body mass } \\ \text { index (kg/m2) }\end{array} & \begin{array}{l}\text { Categorized into (1) }<18.5 ; \text { (2) 18.5-24.9; or } \\ \text { (3) } \geq 25.0 .\end{array} \\ \begin{array}{ll}\text { Birth interval } \\ \text { (months) }\end{array} & \text { Categorized into (1) } \geq 24 \text { and (2) }<24 . \\ \begin{array}{l}\text { Number of under- } \\ \text { fives children }\end{array} & \text { Categorized into (1) 1; (2) 2; (3) 3; or (4) } \geq 4 . \\ \text { Head of household } & \text { Categorized into (1) male or (2) female. } \\ \text { Wealth index } & \begin{array}{l}\text { Categorized into (1) (first quintile) (Poorest); } \\ \text { (2) (second quintile); (3) (third quintile); }\end{array} \\ & \text { (4) (fourth quintile); or (5) (fifth quintile) (Richest) }\end{array}$

Community-level

factors

Residence Poverty rate

Region

Latrine facility type

Drinking water sources characteristics (Level one). Community-level variables describe the cluster of the communities living in the same geographical living environment (Level two). These two hierarchal levels were used to create a multilevel analysis for this study. Communities were based on sharing a common primary sampling unit (cluster) within the EDHS data. A multilevel logistic regression model was applied for three reasons. First, in the EDHS sample, primary sampling unit (PSU) was used to define the clusters. Second, it has been shown that for most of the DHS data, the sample size per cluster meets the optimum size with a tolerable precision loss to do a multilevel analysis [17]. Third, multilevel modeling systematically analyzes how covariates at various levels of hierarchal structure affect the outcome variable and how the interactions among covariates measured at different levels affect the outcome variable. Moreover, multilevel modeling corrects for the biases in parameter estimates resulting from clustering and provides correct standard errors [14].

Data analysis Data analysis was carried out using STATA version 12(StataCorp, College Station, Texas, United States) statistical software and spatial analysis was done using ArcGIS software, version 10.0 (ESRI, Redlands, CA, USA). The authors used the "svy" command in STATA version 12 to weight the survey data as per recommendation of the EDHS. Sample weights were applied in order to compensate for the unequal probability of selection between the strata that were geographically defined, as well as for non-responses. A detailed explanation of the weighting procedure can be found in the EDHS methodology report [10]. Multilevel logistic regression was carried out using STATA version 12data analysis and statistical software.

Spatial analysis Spatial analysis was done using GIS Getis-Ord statistics. The prevalence rates of stunting were exported into ArcGIS to visualize key estimations, and the excess risk of stunting of each region was calculated. Excess risk is defined as a ratio of the observed number over the expected number of cases. In this study, the Local Getis-Ord G index (LGi) was applied to do spatial statistical analysis. The LGi is described in detail in the literature [18]. The spatial heterogeneity of significant high prevalence/low prevalence areas of stunting were computed for each cluster using the Getis-Ord G-statistic tools in ArcGIS. The Local GetisOrd G index helped to classify the autocorrelations into positive and negative correlations. If prevalence rates had similar high values or low values, they were defined as positive autocorrelation hotspots (represented as HighHigh or Low-Low autocorrelation). If the attributes held opposing high and low values, they were considered to have negative autocorrelation (represent as High-Low or
Categorized into (1) piped water; (2) Other improved (protected spring and well, and rain water); (3) unimproved (river, pond, unprotected spring and well). 
Low-High autocorrelation). To determine the significance of these statistics, Z-scores and P-values were used. A Zscore near zero indicates no apparent clustering within the study area. A positive Z-score with P-value of $<0.05$ indicates statistical clustering of hotspots of childhood stunting whereas a negative Z-score with p-value of $<0.05$ indicates statistical clustering of children who are not stunted.

Multilevel logistic regression Multivariable multilevel logistic regression was used to analyze factors associated with childhood stunting at two levels: individual and community (cluster) levels. Four models were constructed for this multilevel logistic regression analysis. The first model was an empty model without any explanatory variables, to evaluate the extent of the cluster variation on stunting. The second model adjusted for the individual-level variables, the third model adjusted for community-level variables while the fourth model adjusted for both the individual- and community-level variables simultaneously. A P-value of $<0.05$ was used to define statistical significance. Adjusted Odds Ratios (AOR) with their corresponding $95 \%$ confidence intervals (CIs) were calculated to identify the independent predictors of stunting. Intra-cluster correlation (ICC), Median Odds Ratio (MOR) and proportional change in variance $(\mathrm{PCV})$ statistics were calculated to measure the variation between clusters. ICC was used to explain cluster variation while MOR is a measure of unexplained cluster heterogeneity [19]. ICC is the measure of variation attributed to contextual neighborhood factors(residential level factors), and is often used to operationalise the concept of contextual phenomena [20]. The ICC was calculated using this formula $\left[I C C=\frac{\tau^{2}}{\left(\tau^{2}+\frac{\pi^{2}}{3}\right)}\right.$, where $\tau^{2}$ is the estimated variance of clusters)] described elsewhere [21]. MOR is defined as the median value of the odds ratio between the area at highest risk and the area at lowest risk when randomly picking out two areas and it was calculated using the formula $\left[\mathrm{MOR}=\exp \left(\sqrt{2 \mathrm{xT}^{2} \times 0.6745}\right) \approx \exp (0.95 \tau)\right]$. In this study MOR shows the extent to which the individual probability of being stunted is determined by residential area [21]. The proportional change in variance (PCV) measures the total variation attributed by individual level factors and area level factors in the multilevel model. MOR and the formula for PCV have been described elsewhere $[20,22,23]$.

\section{Ethical considerations}

The data were downloaded and analyzed after the purpose of the analysis was communicated and approved by MEASURE DHS. The original EDHS data were collected in conformation with international and national ethical guidelines. Ethical clearance for the survey was provided by the Ethiopian Public Health Institute (EPHI), former Ethiopian Health and Nutrition Research Institute (EHNRI) Review Board, the National Research Ethics Review Committee (NRERC) at the Ministry of Science and Technology, the Institutional Review Board of ICF Macro International, and the United States Center for Disease Control and Prevention(CDC).

\section{Results}

\section{Characteristics of the study participants}

Majority of the study subjects $(87.1 \%)$ were from rural area. Most of the mothers $(69.3 \%)$ had no formal education while $50.22 \%$ of their partners had also no formal education. The poorest wealth quintile comprises about $22.8 \%$ of the total population. A total of $11.43 \%$ of the children were infants less than a year. Most of the children had a preceding birth interval of 24 months and above. Only $7.46 \%$ of the households have improved latrine while $10.36 \%$ used piped water as source of drinking water (Table 2).

\section{Spatial variation of stunting}

The overall prevalence of childhood stunting in Ethiopia was $44.5 \%$ (95 \% CI: 43.6-45.5). There were regional variations, with Tigray, Amhara, Afar and BenishangulGumuzregions having a higher prevalence of stunting, while the lowest prevalence of stunting was found in Addis Ababa(Table 3). Rural areas had a higher prevalence of stunting than urban areas. The most excess cases of childhood stunting were found in Amhara, Tigray and Afar regions, while lower excess risk was found in Addis Ababa and Gambella Regions (Table 3).

All zones in Addis Ababa, in Harari, four zones in Oromia region (Jimma, East Wollega, Arsi and West Showa) and two zones in Somali region (Jijiga and Shinile) were significantly clustered with low prevalence of stunting (negative Z-score and Gipvalue $<0.05$ ). Five zones in Amhara region (Kamissie zone, Debub Gonder,SemienWello,Wag Himra and Misrak Gojjam), and Southern zone in Tigray region were significantly clustered with high prevalence of stunting (Positive Z-score and Gipvalue $<0.05$ ). The rest of the zones were not significantly clustered with either low or high prevalence of stunting (Fig. 1).

Figure 2 shows the spatial variation of stunting at the cluster level (lower level). The spatial analysis at the cluster level shows that statistically significant high hotspots of stunting were found in northern parts of the country(Amhara, Benishangul-Gumuz, Tigray and Affar regions), whereas statistically significant low spots of stunting were found in the western (Gambella), central 
Table 2 Socio-demographic and economic characteristics of respondents included in the analysis, 2011 EDHS

\begin{tabular}{|c|c|c|c|c|c|}
\hline Variables & Weighted Frequency & Weighted Percent & Region & & \\
\hline Place of residence & & & Dire Dawa & 39 & 0.3 \\
\hline Urban & 1,528 & 12.9 & Tigray & 753 & 6.3 \\
\hline Rural & 10,344 & 87.1 & Affar & 121 & 1.0 \\
\hline Maternal education & & & Amhara & 2,656 & 22.4 \\
\hline No formal education & 8,227 & 69.3 & Oromiya & 5,014 & 42.2 \\
\hline Primary & 3,211 & 27.0 & Somali & 364 & 3.1 \\
\hline Secondary & 266 & 2.2 & Benishangul-Gumuz & 140 & 1.2 \\
\hline Higher & 168 & 1.4 & SNNP & 2,494 & 21.0 \\
\hline Father's education level & & & Gambela & 40 & 0.3 \\
\hline No education & 5,878 & 50.22 & Harari & 28 & 0.2 \\
\hline Primary & 4,866 & 41.58 & Addis Ababa & 222 & 1.9 \\
\hline Secondary & 584 & 4.99 & Improved latrine facility & & \\
\hline Higher & 376 & 3.22 & Yes & 860 & 7.46 \\
\hline Wealth index & & & No & 10,668 & 92.54 \\
\hline Richest & 2,173 & 15.1 & Drinking water supply & & \\
\hline Richer & 1,870 & 19.1 & Piped water & 616 & 10.36 \\
\hline Middle & 1,872 & 20.5 & Other improved & 1,084 & 18.24 \\
\hline Poorer & 2,114 & 22.4 & Unimproved & 4,243 & 71.39 \\
\hline
\end{tabular}

Child's age(months)

$0-11$
$12-23$
$24-35$
$36-47$
$48-59$
Sex
Female
Male

Anemia

\section{Non-anemic}

Mild

Moderate

Severe

Mother's BMI $\left(\mathrm{kg} / \mathrm{m}^{2}\right)$

$$
\begin{aligned}
& 18.5-24.9 \\
& <18.5
\end{aligned}
$$$$
>=25.0
$$

6,168

Birth interval

$$
\begin{aligned}
& <24 \text { months } \\
& >=24 \text { months }
\end{aligned}
$$

Head of household

Female

$$
1,767
$$

Table 2 Socio-demographic and economic characteristics of respondents included in the analysis, 2011 EDHS (Continued)

(Addis Ababa) and eastern (DireDawa) parts of the country (Table 4 and Fig. 2).

\section{Multilevel analysis}

The results of multilevel logistic regression models for individual and community level factors are displayed in Table 5. In the final full model where all individual and community level factors are included, child's age; gender; birth interval; maternal body mass index (BMI); education status of mother; educational status of father; sex of the household head; child's anemia status; low household wealth index; region; and lack of availability of an improved latrine were factors that were significantly associated with childhood stunting.

\section{Individual level factors}

Children 24-35 months old were 6.61 times $(\mathrm{AOR}=6.61$; $95 \%$ CI: 5.17-8.44) more likely to be stunted than children less than one year old. The odds of stunting were increased by $20 \%$ (AOR $=1.20$; $95 \%$ CI: $1.08-1.33$ ) in male children compared to females. The odds of stunting among children with severe anemia were 3.32 times higher $(\mathrm{AOR}=3.23$; $95 \% \mathrm{CI}$ : 2.35-4.43) than in children with no anemia. Children with mothers who completed higher education were 58 \% (AOR $=0.42$; 95 \% CI: 0.18 0.94) less likely to be stunted compared to those children whose mothers had no formal education. The odds of stunting were $42 \%$ lower among children with fathers who 
Table 3 Regional variation of prevalence rate and risk of stunting in Ethiopia, DHS 2011

\begin{tabular}{lllll}
\hline Region & \multicolumn{2}{l}{ Weighted number } & \begin{tabular}{l} 
Weighted \\
Prevalence of \\
stunting \\
\cline { 2 - 3 }$(95 \%$ Cl)
\end{tabular} & $\begin{array}{l}\text { Excess } \\
\text { Risk }\end{array}$ \\
\cline { 2 - 3 } Stunted & Normal & 332 & $51.0(47.3-54.8)$ & 1.15 \\
Afar & 346. & 50 & $51.0(41.3-60.6)$ & 1.15 \\
Amhara & 1175 & 1,088 & $51.9(49.9-54.0)$ & 1.17 \\
Oromiya & 1,838 & 2,594 & $41.5(40.0-43.0)$ & 0.93 \\
Somali & 92 & 189 & $32.7(27.5-38.5)$ & 0.73 \\
Benishangul-Gumuz & 58 & 60 & $49.4(40.2-58.1)$ & 1.11 \\
SNNP & 965 & 1204 & $44.5(42.4-46.6)$ & 1.0 \\
Gambella & 9 & 23 & $28.0(14.7-45.4)$ & 0.63 \\
Harari & 7 & 16 & $30.3(14.4-51.1)$ & 0.68 \\
Addis Ababa & 39 & 144 & $21.7(15.8-27.6)$ & 0.48 \\
Dire Dawa & 12 & 22 & $36.4(21.4-53.6)$ & 0.79 \\
Place of Residence & & & & \\
$\quad$ Urban & 391 & 876 & $30.8(28.4-33.5)$ & 0.69 \\
$\quad$ Rural & 4,202 & 4,844 & $46.4(45.4-47.5)$ & 1.04 \\
Total & 4,593 & 5721 & $44.5(43.6-45.5)$ & \\
\hline
\end{tabular}

${ }^{a}$ South Nation, Nationalities and region people

completed higher education ( $\mathrm{AOR}=0.58$; 95 \% CI: $0.38-$ $0.89)$ compared to children whose fathers had no formal education.

Children with mothers who had a high BMI $(\geq 25.0 \mathrm{~kg} /$ $\left.\mathrm{m}^{2}\right)(\mathrm{AOR}=0.69 ; 95 \% \mathrm{CI}: 0.52-0.90)$ were less likely to be stunted compared with children whose mothers had normal BMI $\left(18.5 \mathrm{~kg} / \mathrm{m}^{2}-24.9 \mathrm{~kg} / \mathrm{m}^{2}\right)$. The odds of being stunting were $68 \%$ higher among children with a shorter $(<24$ months) birth interval compared to children with longer birth interval ( $\geq 24$ months) (AOR = 1.68; 95 \% CI: 1.46-1.93). Children from the poorest wealth quintile had $43 \%$ higher odds of being stunted compared with children from the richest wealth quintile ( $\mathrm{AOR}=1.43 ; 95$ \% CI: 1.08-1.88). Children from maleheaded households were $18 \%$ more likely to be stunted compared to children from female-headed households $(\mathrm{AOR}=1.18 ; 95 \% \mathrm{CI}: 1.01-1.38)$.

\section{Community level factors}

Children from households without access to an improved latrine (defined as private and hygienic with a cleanable slab) had $26 \%$ higher odds of stunting compared to children from households that reported access to an improved latrine $(\mathrm{AOR}=1.26$; $95 \% \mathrm{CI}: 1.01-1.59)$. The odds of childhood stunting in Tigray (AOR $=1.58$; $95 \% \mathrm{CI}$ : 1.09-2.29), Amhara (AOR 1.50; 95 \% CI 1.04-2.17) and BenishangulGumuz(AOR =1.71; 95 \% CI: 1.16-2.52) were higher compared to Dire Dawa respectively. However the odds of childhood stunting at Gambella region were lower by $43 \%$ as compared to Dire Dawa $(\mathrm{AOR}=0.57$; $95 \% \mathrm{CI}$ : 0.37-0.86) (Table 5).

As shown in Table 6, the empty model (the null model) revealed that childhood stunting was not random across the communities $\left(\tau^{2}=0.363, P<0.001\right)$. About $9.9 \%$ of the variance in the odds of childhood stunting could be attributed to the community level factors as calculated by the ICC based on estimated intercept component variance. The full model, after adjusting for individual and community level factors, shows that the variation in childhood stunting across communities remained statistically significant. About $36.6 \%$ of the odds of childhood stunting variation across communities was observed in the full model.

Moreover, the MOR confirmed that childhood stunting was attributed to community level factors. The MOR for stunting was 2.01 in the empty model; this indicated that there is variation between communities (clustering) since MOR is two times higher than the reference $(\mathrm{MOR}=1)$. The unexplained community variation in stunting decreased to MOR of 1.75 when all factors were added to the null model (empty model). This shows that when all factors are considered, the effect of clustering is still statistically significant in the full model.

\section{Discussion}

This study found that the prevalence of stunting was above the national average of $44 \%$ in six out of the eleven regions of the country. Excess cases of stunting were found in the northern parts of the country characterized by highlands and midlands. This finding is consistent with the study done by Hagos et al. which found that a higher prevalence of stunting was found in the highlands and midlands compared to the lowlands [24]. That study concluded that rainfall and temperature are the main predictors of stunting variation across the country. Other studies also showed that climate change could indeed increase stunting rates in areas of the country dependent on rain-fed agriculture $[25,26]$. The spatial variation of childhood stunting is also determined by environmental or geographical factors (e.g. population density, climate and disease environment) in addition to the individual and household level factors [27]. In this study Getis-Ord spatial statistics showed spatial variation of childhood stunting at the cluster level. Statistically significant hotspot areas of childhood stunting were found particularly in the northern parts of the country, in Benishangul-Gumuz, Amhara, Tigray and Affar regions, when we compare to clusters found in other regions. Exploring spatial variation is important to identify aggregations of cases in order to target nutritional interventions [8]. The identified clusters might be the areas where childhood stunting prevention and control interventions should be given priority [28]. 


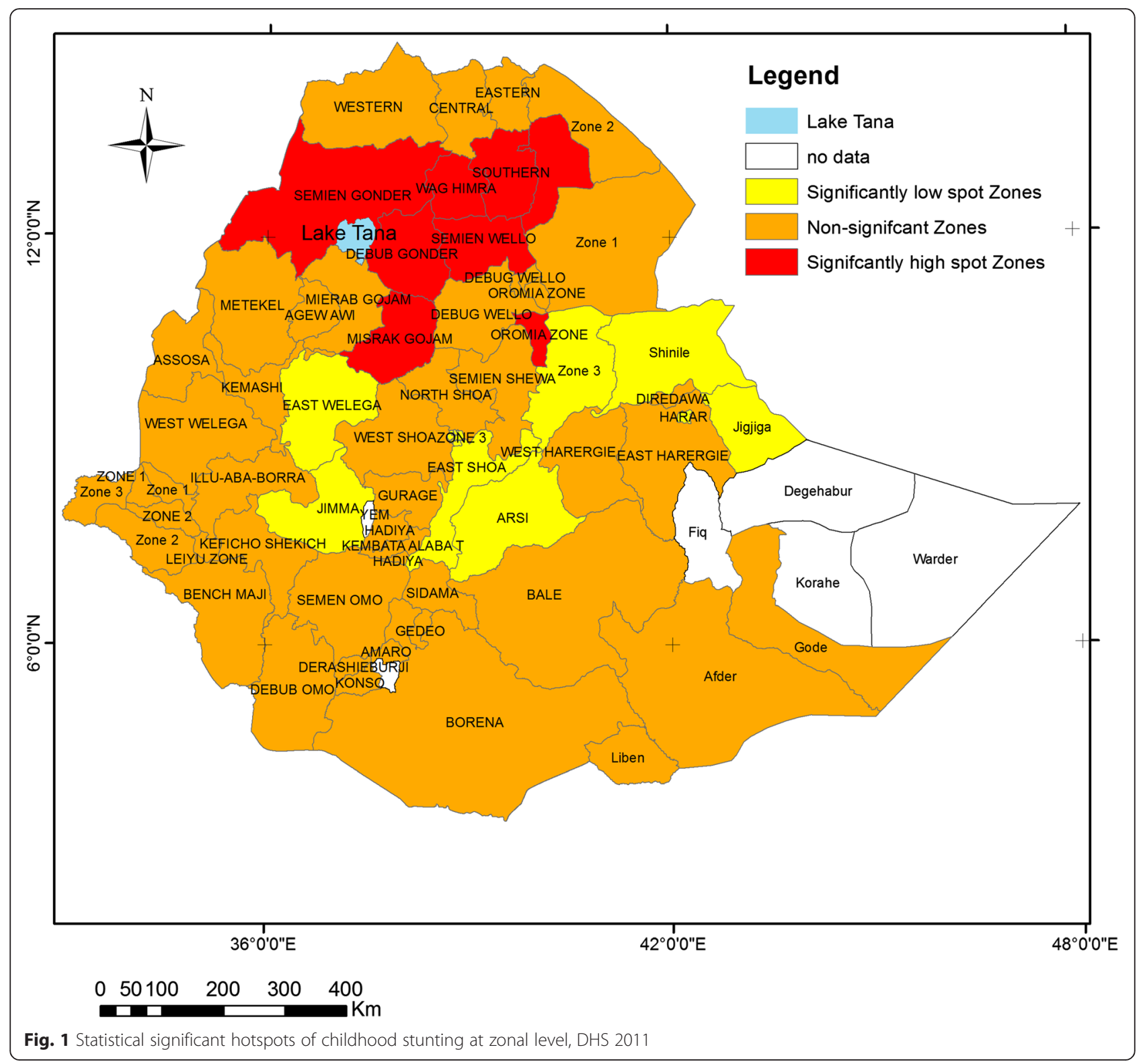

This study confirmed that the variation in childhood stunting can be attributed to both individual and community level factors. In the final model, individual and community-level factors accounted for about $36.6 \%$ of the variation observed for childhood stunting. The national average for stunting in children under five years of age in Ethiopia is $44.4 \%$. Children aged $>12$ months were at higher odds of being stunted compared to infants of less than one year. The trend of stunting increased for each age group of children age up to 35 months, and then declined to just under $50 \%$ for children aged 48-59 months. This finding is consistent with many previous studies [29-34]. These studies reported that there is a rapid fall in children's height-for-age Z-score from birth to 24 months, particularly during the time when children are being weaned off of exclusive breastfeeding and also becoming more mobile and crawling. These activities expose the child to contaminants in water and food, as well as soil and contaminants picked up on their hands that then go into their mouths. There continues to be an increase in stunting after 24 months, but the rate of increase is much slower. The cumulative effect in older age children might be one possible justification for this pattern. Studies report that children living in most developing countries are introduced directly to the regular household diet made of cereal or starchy root crops, which is the major cause for the high incidence of child malnutrition and morbidity [35-37]. Another article found that linear growth failure occurs within a complex interplay of more distal community and societal factors, 


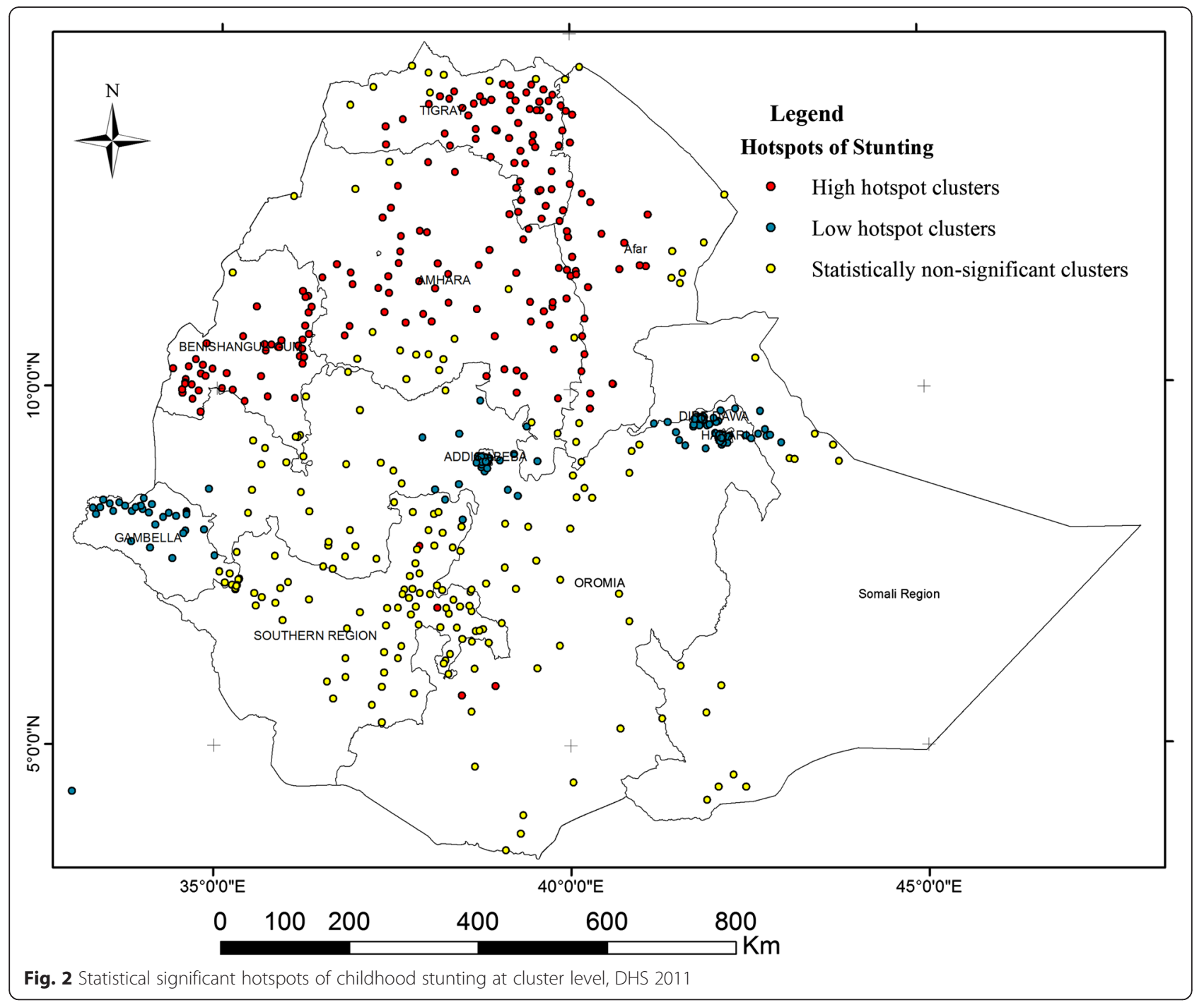

Table 4 Hotspot and coldspot analysis of stunting among enumeration areas (clusters) per regional state in Ethiopia, EDHS 2011

\begin{tabular}{|c|c|c|c|c|}
\hline Region & Total number of clusters & High hotspots* & Low hotspots** & Non-significant clusters*** \\
\hline Tigray & 58 & 52 & 1 & 5 \\
\hline Afar & 42 & 28 & 2 & 12 \\
\hline Amhara & 68 & 40 & 4 & 14 \\
\hline Oromiya & 73 & 3 & 21 & 49 \\
\hline Somali & 35 & - & 16 & 19 \\
\hline Benishangul-Gumuz & 46 & 39 & 1 & 6 \\
\hline SNNP & 79 & 1 & 3 & 75 \\
\hline Gambela & 46 & 1 & 33 & 12 \\
\hline Harari & 42 & - & 39 & 3 \\
\hline Addis Ababa & 52 & - & 49 & 3 \\
\hline Dire Dawa & 40 & - & 39 & 1 \\
\hline
\end{tabular}

${ }^{*}$ GiZScore positive (1.968-4.68) and $p$-value $<0.05$

${ }^{*}$ GiZScore negative $(-6.42$ to -2.623$)$ and $p$-value $<0.05$

***GiZScore either positive or negative and $p$-value $>=005$ 
Table 5 Factors associated with childhood stunting in Ethiopia by multilevel logistic regression analysis, EDHS 2011

\begin{tabular}{|c|c|c|c|}
\hline \multirow[t]{2}{*}{ Variables } & Model 2 & Model 3 & Model 4 \\
\hline & AOR(95 \% Cl) & $\mathrm{AOR}(95 \% \mathrm{Cl})$ & AOR(95 \% Cl) \\
\hline \multicolumn{4}{|c|}{ Individual level factors } \\
\hline \multicolumn{4}{|l|}{ Child factors } \\
\hline \multicolumn{4}{|c|}{ Child's age(months) } \\
\hline $0-11$ & 1.00 & & 1.00 \\
\hline $12-23$ & $4.13(3.23-5.27)$ & & $4.12(3.22-5.26)$ \\
\hline $24-35$ & $6.47(5.07-8.25)$ & & $6.61(5.17-8.44)$ \\
\hline $36-47$ & $6.37(5.00-8.10)$ & & $6.44(5.10-8.20)$ \\
\hline $48-59$ & $5.58(4.38-7.12)$ & & $5.65(4.43-7.21)$ \\
\hline \multicolumn{4}{|l|}{ Sex } \\
\hline Female & 1.00 & & 1.00 \\
\hline Male & $1.20(1.08-1.37)$ & & $1.20(1.08-1.33)$ \\
\hline \multicolumn{4}{|l|}{ Immunization } \\
\hline Complete & 1.00 & & 1.00 \\
\hline Incomplete & $1.01(0.76-1.34)$ & & $1.01(0.76-1.34)$ \\
\hline \multicolumn{4}{|l|}{ Anemia } \\
\hline Non-anemic & 1.00 & & 1.00 \\
\hline Mild & $1.36(1.18-1.56)$ & & $1.43(1.24-1.64)$ \\
\hline Moderate & $1.64(1.42-1.89)$ & & $1.76(1.52-2.03)$ \\
\hline Severe & $2.93(2.14-4.01)$ & & $3.23(2.35-4.43)$ \\
\hline \multicolumn{4}{|c|}{ Maternal/household factors } \\
\hline \multicolumn{4}{|c|}{ Mother's age (years) } \\
\hline $15-24$ & 1.00 & & 1.00 \\
\hline $25-34$ & $0.95(0.82-1.10)$ & & $0.96(0.83-1.11)$ \\
\hline $35-49$ & $0.92(0.76-1.10)$ & & $0.93(0.77-1.12)$ \\
\hline \multicolumn{4}{|l|}{ Maternal education } \\
\hline No education & 1.00 & & 1.00 \\
\hline Primary & $0.88(0.76-1.02)$ & & $0.90(0.78-1.04)$ \\
\hline Secondary & $0.64(0.41-1.01)$ & & $0.70(0.44-1.10)$ \\
\hline Higher & $0.43(0.19-0.97)$ & & $0.42(0.18-0.94)$ \\
\hline \multicolumn{4}{|c|}{ Mother's BMI $\left(\mathrm{kg} / \mathrm{m}^{2}\right)$} \\
\hline $18.5-24.9$ & 1.00 & & 1.00 \\
\hline$<18.5$ & $1.08(0.95-1.22)$ & & $1.13(1.00-1.28)$ \\
\hline$>=25.0$ & $0.65(0.49-0.85)$ & & $0.69(0.52-0.90)$ \\
\hline \multicolumn{4}{|l|}{ Birth interval } \\
\hline$<24$ months & 1.00 & & 1.00 \\
\hline$>=24$ months & $1.72(1.50-1.98)$ & & $1.68(1.46-1.93)$ \\
\hline \multicolumn{4}{|c|}{ Number of under five children } \\
\hline One & 1.00 & & 1.00 \\
\hline Two & $0.88(0.77-1.01)$ & & $0.90(0.79-1.03)$ \\
\hline Three & $0.88(0.73-1.06)$ & & $0.95(0.79-1.14)$ \\
\hline Four & $0.79(0.58-1.19)$ & & $0.90(0.61-1.33)$ \\
\hline \multicolumn{4}{|l|}{ Head of household } \\
\hline Female & 1.00 & & 1.00 \\
\hline
\end{tabular}


Table 5 Factors associated with childhood stunting in Ethiopia by multilevel logistic regression analysis, EDHS 2011 (Continued)

\begin{tabular}{|c|c|c|c|}
\hline Male & $1.14(0.98-1.32)$ & & $1.18(1.01-1.38)$ \\
\hline \multicolumn{4}{|l|}{ Father's education level } \\
\hline No education & 1.00 & & 1.00 \\
\hline Primary & $0.98(0.87-1.11)$ & & $0.98(0.87-1.12)$ \\
\hline Secondary & $0.64(0.49-0.85)$ & & $0.74(0.56-0.99)$ \\
\hline Higher & $0.50(0.33-0.76)$ & & $0.58(0.38-0.89)$ \\
\hline \multicolumn{4}{|l|}{ Family size } \\
\hline$\leq 4$ & 1.00 & & 1.00 \\
\hline $5-7$ & $1.03(0.88-1.20)$ & & $1.03(0.88-1.20)$ \\
\hline $8-10$ & $1.05(0.86-1.27)$ & & $1.05(0.86-1.28)$ \\
\hline$\geq 11$ & $1.21(0.86-1.71)$ & & $1.20(0.84-1.70)$ \\
\hline \multicolumn{4}{|l|}{ Wealth index } \\
\hline Richest & 1.00 & & 1.00 \\
\hline Richer & $1.74(1.39-2.17)$ & & $1.46(1.12-1.90)$ \\
\hline Middle & $1.57(1.25-1.98)$ & & $1.24(0.94-1.64)$ \\
\hline Poorer & $1.82(1.45-2.29)$ & & $1.42(1.08-1.88)$ \\
\hline Poorest & $1.73(1.39-2.17)$ & & $1.43(1.08-1.89)$ \\
\hline \multicolumn{4}{|l|}{ Community level factors } \\
\hline \multicolumn{4}{|l|}{ Place of residence } \\
\hline Urban & & 1.00 & 1.00 \\
\hline Rural & & $1.79(1.49-2.16)$ & $1.18(0.88-1.60)$ \\
\hline \multicolumn{4}{|l|}{ Poverty rate } \\
\hline Low & & 1.00 & 1.00 \\
\hline High & & $1.02(0.88-1.20)$ & $1.01(0.84-1.23)$ \\
\hline \multicolumn{4}{|l|}{ Region } \\
\hline Dire Dawa & & 1.00 & 1.00 \\
\hline Tigray & & $1.63(1.23-2.16)$ & 1.58(1.09-2.29) \\
\hline Affar & & $1.65(1.23-2.21)$ & $1.27(0.86-1.86)$ \\
\hline Amhara & & $1.62(1.23-2.15)$ & $1.50(1.04-2.17)$ \\
\hline Oromiya & & $1.01(0.77-1.32)$ & $1.13(0.79-1.62)$ \\
\hline Somali & & $0.80(0.59-1.09)$ & $0.68(0.46-1.01)$ \\
\hline Benishangul-Gumuz & & $1.49(1.11-2.01)$ & $1.71(1.16-2.52)$ \\
\hline SNNP & & $1.17(0.89-1.54)$ & $1.43(1.00-2.06)$ \\
\hline Gambela & & $0.57(0.47-0.78)$ & $0.57(0.37-0.86)$ \\
\hline Harari & & $0.73(0.52-1.01)$ & $0.72(0.46-1.12)$ \\
\hline Addis Ababa & & $0.78(0.53-1.14)$ & $1.03(0.57-1.83)$ \\
\hline \multicolumn{4}{|c|}{ Improved latrine facility } \\
\hline Yes & & 1.00 & 1.00 \\
\hline No & & $1.27(1.07-1.51)$ & $1.26(1.01-1.59)$ \\
\hline \multicolumn{4}{|l|}{ Drinking water supply } \\
\hline Piped water & & 1.00 & 1.00 \\
\hline Other improved & & $1.13(0.97-1.32)$ & $1.03(0.85-1.25)$ \\
\hline Unimproved & & $1.06(0.87-1.29)$ & $1.04(0.87-1.24)$ \\
\hline
\end{tabular}


Table 6 Results from random intercept model (measure of variation) for childhood stunting at cluster level by multilevel logistic regression analysis

\begin{tabular}{|c|c|c|c|c|c|c|c|c|}
\hline Measure of variation & Model $1^{a}$ & P-value & Model $2^{b}$ & $p$-value & Model $3^{c}$ & $p$-value & Model $4^{d}$ & $\mathrm{p}$-value \\
\hline \multicolumn{9}{|l|}{ Community level } \\
\hline Variance (SE) & $0.363(0.043)$ & $<0.001$ & $0.323(0.050)$ & $<0.001$ & $0.159(0.046)$ & $<0.001$ & $0.230(0.041)$ & $<0.01$ \\
\hline Explained variation(PCV) & Reference & & 11.0 & & 56.2 & & 36.6 & \\
\hline ICC (\%) & 9.9 & & 8.9 & & 4.6 & & 6.5 & \\
\hline MOR & 2.10 & & 1.93 & & 1.59 & & 1.75 & \\
\hline \multicolumn{9}{|l|}{ Model fit statistics } \\
\hline DIC (-2log likelihood) & 13256 & & 8499 & & 12733 & & 8357 & \\
\hline
\end{tabular}

SE standard error, ICC intracluster correlation, MOR median odds ratio, DIC deviation information criterion

${ }^{a}$ Model 1 is the empty model, a baseline model without any determinant variable

${ }^{b}$ Model 2 is adjusted for individual-level factors

${ }^{c}$ Model 3 is adjusted for community-level factors

${ }^{\mathrm{d}}$ Model 4 is final model adjusted for both individual and community-level factors

such as access to healthcare and education, political stability, urbanisation, population density and social support networks [38].

This study found that male children had a slightly higher chance of being stunted than females. This result is consistent with previous studies [31, 39-41]. One possible explanation for this could be that childhood morbidity is higher among males than females in early life, even after adjusting for gestational age and body size [42]. Moreover, the proportion of male preterm births is higher than female preterm births which could also contribute to childhood stunting [39, 42-44]. However there are also studies which showed that stunting was not significantly associated with sex [32, 45], and programmatically this difference in stunting rates may not be useful for targeting interventions.

Maternal education was found to be significantly negatively associated with childhood stunting. Many previous studies have found that maternal education has a positive effect on reducing childhood stunting $[29,31,46-51]$. The knowledge that mothers acquire from formal education could help them to adopt essential nutrition and hygiene behaviors that prevent childhood stunting. Another possible reason might be that educated mothers have better health-seeking behavior for childhood illnesses as compared to uneducated mothers which can help prevent stunting [52, 53]. Besides maternal education, father's education was also significantly associated with childhood stunting. Those children whose fathers had attended formal education had less chance of being stunted. Similar findings have been reported by other studies [46, 54]. Those fathers with formal education might be more knowledgeable on proper child feeding and hygiene practices, which have a positive effect on preventing childhood stunting. Father's higher education has also been associated with good health seeking behavior for childhood illness [55]. In Ethiopia lack of education is a widespread problem, about
$59 \%$ and $33 \%$ of the women and men were illiterate, respectively which shows how this factor is important in prevention of stunting in Ethiopia [10].

The socioeconomic status of households is associated with access to nutritious foods at the household level, which in turn determines the growth and development of children [56]. Findings of this study revealed that children from households in the poorest wealth quintile were more likely to be stunted than children from the richest quintile, which is consistent with the findings of previous studies carried out in different developing countries [29, 46-49, 57-59]. This could be due to the fact that increased income improves dietary diversity $[60,61]$, which in turn improves the adequacy of nutrient intake and nutritional status, and underscores the importance of linking income generating activities with other nutritional interventions. In Ethiopia, above $45 \%$ of the population was found in poor and poorest wealth quintile, which shows the proportion of children who are at risk for stunting due to low socioeconomic status [10].

The 2014 Mini EDHS data show that only $9.7 \%$ of the population had access to an improved and shared latrine facilities [62]. This study found that the availability of an improved latrine was one of the significant factors associated with childhood stunting, which is consistent with other studies conducted in developing countries [41, 63]. One explanation could be a reduction in the pathogen load in the environment from correct and consistent use of improved sanitation, since exposure to feces has been linked to environmental enteropathy and stunting [64-66].

A short birth interval is common in Ethiopia and a known risk factor for stunting $[67,68]$. Twenty percent of the births have an interval of less than two years, and 9 percent of births are less than 18 months apart. This implies that $20 \%$ of the Ethiopian children were at risk of stunting attributable to short birth interval [10]. This 
study found that having a birth interval $\geq 24$ months decreased the odds of being stunted. This is consistent with other studies [68, 69].A short interval between births can have an adverse effect on child nutrition by causing intrauterine growth retardation, and/or undermining the quality of child care [70].

Birth spacing might also influence childhood undernutrition through its association with preterm births and low birth weight. If a pregnancy occurs too soon after the previous birth, the mother may not recover her nutritional status, which can contribute to preterm birth and low birth weight [68]. Maternal nutritional status was associated with childhood stunting in this study. The prevalence of under nutrition $(\mathrm{BMI}<18.5 \mathrm{~kg} / \mathrm{m})$ among women in Ethiopia was $27 \%$ [10]. Mothers who had a BMI $<18.5 \mathrm{~kg} / \mathrm{m}^{2}$ were marginally associated with higher odds of childhood stunting compared to mothers with normal BMI $\left(18.5 \mathrm{~kg} / \mathrm{m}^{2}-24.9 \mathrm{~kg} / \mathrm{m}^{2}\right)$. Mothers who had BMI $\geq 25 \mathrm{~kg} / \mathrm{m}^{2}$ wereless likely to have child who is stunted. A study from Brazil also suggested that maternal nutritional status was associated with child nutritional status [71]. A study from Cambodia also found that maternal BMI was associated with childhood stunting [69].

The representativeness of the data with a large sample size, as well as a nationally representative populationbased study with a high response rate are strengths of this study that give high statistical power to infer the characteristics of the study population. Another important strength of this study is the use of multilevel logistic regression analysis, which was able to identify other factors beyond individual-level factors that would not be identified by using standard logistic regression analysis. The use of a combination of methods (spatial and regression statistics) was a strength which allowed validation of the identified hotspots areas due to the assumptions of the statistical methods. One limitation is that the crosssectional nature of the study means the results cannot be used to establish cause and effect relationship, and is a limitation of the study. Another limitation is the absence of other important variables like behavioral factors and quantitative dietary consumption to substantiate the findings, since the EDHS survey was designed to produce health and health related indices, but was not specifically administered for the purposes of this study.

\section{Conclusion}

This study found that childhood stunting was not random in Ethiopia. Statistically significant high hotspots of stunting were found in northern parts of the country whereas low hotspots of stunting were found in central, eastern, western parts of the country. Individual and community level factors accounted for $36.6 \%$ of the variation in childhood stunting across the communities.
Both individual- and community-level factors were significant determinants of childhood stunting. Being male, age above 11 months, short birth interval, having anemia, no formal education of mother and/or father, being from male-headed household, and being from a household in the lowest wealth quintile were the factors that increased the odds of stunting at the individual level, whereas a lack of access to an improved latrine and residence in the northern regions of the country were the factors associated with stunting at the community level.

Thus, the improvement of nutritional status of children requires multi-factorial interventions such as reducing poverty and ensuring food security, ensuring adequate birth interval, educating mothers and their partners, a healthy environment and good hygienic practices enabled by access to hygienic latrines. The regions identified as having high hotspots of childhood stunting should be prioritized for nutritional interventions.

\section{Abbreviations \\ AOR: adjusted odds ratio; Cl: confidence intervals; EDHS: Ethiopian demographic health survey; GIS: geographic information system; HAZ: height-for-age; ICC: intra-cluster correlation; MOR: median odds ratio; PCV: proportional change in variance; SD: standard deviation; WHO: world health organization.}

\section{Competing interest}

The authors declare that they have no competing interest.

\section{Authors' contributions}

DH conceived the study, assisted the data analysis and interpretation, drafted the manuscript and critically reviewed the manuscript. MA conceived the study, conducted the data analysis and interpretation, and critically reviewed the manuscript. TM assisted the data analysis, critically reviewed the manuscript. RR critically reviewed the manuscript and did final editing. All of the authors read and approved the final version of the manuscript

\section{Acknowledgments}

The data used in this study were obtained from MEASURE DHS Archive and the authors acknowledge MEASURE DHS for allowing us to use the data. The analysis and the interpretation of the findings in this study are the responsibility of authors and do not necessarily reflect the views of MEASURE DHS. We thank Mr. Tesfaye Sorresa for editing the language and typological errors of this manuscript.

\section{Author details}

'Department of Public Health, College of Medicine and Health Sciences, Bahir Dar University, P.O. Box 79, Bahir Dar, Ethiopia. ${ }^{2}$ Department of Geography and Environmental Studies, Bahir Dar University, P.O. Box 79, Bahir Dar, Ethiopia. ${ }^{3}$ United States Agency for International Development (USAID), Washington, DC, USA.

Received: 2 December 2014 Accepted: 12 April 2016

Published online: 15 April 2016

\section{References}

1. WHO(World Health Organization). Physical status: the use and interpretation of anthropometry. Geneva: World Health Organization, 1995; 2006. p. 36. Technical report no.854.

2. Berkman DS, Lescano AG, Gilman RH, Lopez SL, Black MM. Effects of stunting, diarrhoeal disease, and parasitic infection during infancy on cogni-tion in late childhood:a follow-up study. Lancet. 2002;359:564-71.

3. Victora CG, Adair L, Fall C, Hallal PC, Martorell R, Richter L, Sachdev HS, Maternal and Child Undernutrition Study Group. Maternal and child undernutrition: consequences for adult health and human capital. Lancet. 2008;371(9609):340-57. 
4. Black RE, Allen LH, Bhutta ZA, Caulfield LE, deOnis M, Ezzati M, et al. Maternal and child undernutrition: global and regional exposures and health consequences. Lancet. 2008;371:243-60.

5. Gluckman PD, Hanson MA, Beedle AS. Early life events and their consequences for later disease: a life history and evolutionary perspective. Am J Hum Biol. 2007:19:1-19.

6. Uauy R, Kain J, Mericq V, Rojas J, Corvalan C. Nutrition, child growth, and chronic disease prevention. Ann Med. 2008;40:11-20.

7. Black RE, Victora CG, Walker SP, Bhutta ZA, Christian P, de Onis M, et al. Maternal and child undernutrition and overweight in low-income and middle-income countries. Lancet. 2013;382:427-51.

8. Adekanmbi VT, Uthman OA, Mudasiru OM. Exploring variations in childhood stunting in Nigeria using league table, control chart and spatial analysis. BMC Public Health. 2013;13:361.

9. Central statistical agency -Ethiopia. Ethiopia Demographic and Health Survey. 2000

10. Central Statistical Agency (CSA)Ethiopia. Ethiopia Demographic and Health Survey 2011. Addis Ababa, Ethiopia and Calverton, Maryland: CSA and ORC Macro; 2012.

11. Government of the Federal Democratic Republic of Ethiopia. National Nutrition Programme, June 2013 - June 2015. 2013.

12. Mengistu K, Alemu K, Destaw B. Prevalence of Malnutrition and Associated Factors Among Children Aged 6-59 Months at Hidabu Abote District, North Shewa, Oromia Regional State. Nutritional Disorders Therapy. 2013;T1:001.

13. Tariku B, Mulugeta A, Tsadik M, Azene G. Prevalence and Risk Factors of Child Malnutrition in Community Based Nutrition Program Implementing and Nonimplementing Districts from South East Amhara, Ethiopia. Open Access Library J. 2014;1:1-17.

14. Guo G, Zhao H. Multilevel Modeling for Binary Data. Annual Review Sociology. 2000;26:441-62.

15. WHO/Multi Growth Resaerch Center Study Group (MGRSG. Complementary feeding in the WHO Multicentre Growth Reference Study. Acta Pediatrica. 2006;450:27-37.

16. Rutstein SO: The DHS Wealth Index: Approaches for Rural and Urban Areas. DHS Working Papers. Demographic And Health Research 2008(60). Available at http://www.dhsprogram.com/pubs/pdf/WP60/WP60.pdf. Accessed 20 Oct 2013.

17. Kravdal O. A simulation-based assessment of the bias produced when using averages from small DHS clusters as contextual variables in multilevel models. Demographic Res. 2006;15:1-20.

18. Ord JK, Getis A. Local Spatial Autocorrelation Statistics: Distributional Issues and an Application. Geographical Analysis. 1995;27(4):286-306.

19. Halonen Jl, Kivimaki M, Pentti J, Kawachi I, Virtanen M, Martikainen P, Subramanian SV, Vahtera J. Quantifying neighbourhood socioeconomic effects in clustering of behaviour-related risk factors: a multilevel analysis. PLoS One. 2012;7(3):e32937.

20. Merlo J, Chaix B, Yang M, Lynch J, Rastam L. A brief conceptual tutorial of multilevel analysis in social epidemiology: linking the statistical concept of clustering to the idea of contextual phenomenon. J Epidemiol Community Health. 2005;59(6):443-9.

21. Merlo J, Chaix B, Ohlsson H, Beckman A, Johnell K, Hjerpe P, Rastam L, Larsen K. A brief conceptual tutorial of multilevel analysis in social epidemiology: using measures of clustering in multilevel logistic regression to investigate contextual phenomena. J Epidemiol Community Health. 2006; 60(4):290-297.

22. Larsen K, Merlo J. Appropriate assessment of neighborhood effects on individual health: integrating random and fixed effects in multilevel logistic regression. Am J Epidemiol. 2005;161(1):81-8.

23. Merlo J, Yang M, Chaix B, Lynch J, Rastam L. A brief conceptual tutorial on multilevel analysis in social epidemiology: investigating contextual phenomena in different groups of people. J Epidemiol Community Health 2005;59(9):729-36.

24. Hagos S, Lunde T, Mariam DH, Woldehanna T, Lindtjorn B. Climate change crop production and child under nutrition in Ethiopia; a longitudinal panel study. BMC Public Health. 2014;14:884

25. Grace K, Davenport F, Funk C, Lerner AM. Child malnutrition and climate in Sub-Saharan Africa: An analysis of recent trends in Kenya. Applied Geography. 2012;35:405-13.

26. Jankowskaa MM, Lopez-Carr D, Funk C, Husak GJ, Chafe ZA. Climate change and human health: Spatial modeling of water availability, malnutrition, and livelihoods in Mali, Africa. Applied Geography. 2011;1-12.
27. Balk D, Pullum T, Storeygard A, Greenwell F, Neuman M. A spatial analysis of childhood mortality in West Africa. Population Space Place. 2004;10(3):175-216.

28. Khamis FG, El-Refae GA. Association between Spatial Patterns of Acute Malnutrition and Household Income in Iraq-2004. Int J Statistics Probability. 2012;1(1):43-52.

29. Kabubo-Mariara J, Ndenge GK, Mwabu DK. Determinants of children's nutritional status in Kenya: evidence from demographic and health surveys. J African Economies. 2009;18:363-87.

30. Shrimpton R, Victora CG, de Onis M, Lima RC, Blossner M, Clugston G. Worldwide timing of growth faltering: implications for nutritional interventions. Pediatrics. 2001;107(5):E75.

31. Adekanmbi VT, Kayode GA, Uthman OA. Individual and contextual factors associated with childhood stunting in Nigeria: a multilevel analysis. Matern Child Nutr. 2013;9(2):244-59.

32. Mushtaq MU, Gull S, Khurshid U, Shahid U, Shad MA, Siddiqui AM. Prevalence and socio-demographic correlates of stunting and thinness among Pakistani primary school children. BMC Public Health. 2011;11:790.

33. Wand H, Lote $N$, Semos I, Siba P. Investigating the spatial variations of high prevalences of severe malnutrition among children in Papua New Guinea: results from geoadditive models. BMC Res Notes. 2012;5:228.

34. Fenske N, Burns J, Hothorn T, Rehfuess EA. Understanding Child Stunting in India: A Comprehensive Analysis of Socio-Economic, Nutritional and Environmental Determinants Using Additive Quantile Regression. PLoS One. 2013;8(11):78692.

35. Dewey K, Brown K. Update on Technical Issues Concerning Complementary Feeding of Young Children in Developing Countries and Implications for Intervention Programs. Food Nutr Bull. 2003;24:5-28.

36. Krebs N, Westcott J. Zinc and Breastfed Infants: If and When Is There a Risk of Deficiency? Adv Exp Med Biol. 2002;503:69-75.

37. WHO/UNICEF. Complementary Feeding of Young Children in Developing Countries: A Review of Current Scientific Knowledge. Geneva: WHO/NUT/ 981 World Health Organization; 1998. p. 1-228.

38. Stewart CP, lannotti L, Dewey KG, Michaelsen KF, Onyango AW Contextualising complementary feeding in a broader framework for stunting prevention. Matern Child Nutr. 2013;9 Suppl 2:27-45.

39. Ingemarsson I. Gender aspects of preterm birth. BJOG. 2003;110 Suppl 20:34-8.

40. Wamani H, Astrom AN, Peterson S, Tumwine JK, Tylleskar T. Boys are more stunted than girls in sub-Saharan Africa: a meta-analysis of 16 demographic and health surveys. BMC Pediatr. 2007;7:17.

41. Keino S, Plasqui G, Ettyang G, van den Borne B. Determinants of stunting and overweight among young children and adolescents in sub-Saharan Africa. Food Nutr Bull. 2014;35(2):167-78.

42. Elsmen E, Hansen Pupp I, Hellstrom-Westas L. Preterm male infants need more initial respiratory and circulatory support than female infants. Acta Paediatrica. 2004;93(4):529-33.

43. Escobar GJ, Clark RH, Greene JD. Short-term outcomes of infants born at 35 and 36 weeks gestation: we need to ask more questions. Semin Perinatol. 2006;30(1):28-33.

44. Kilbride HW, Daily DK. Survival and subsequent outcome to five years of age for infants with birth weights less than 801 grams born from 1983 to 1989. J Perinatology. 1998;18(2):102-6.

45. Bloss E, Wainaina F, Bailey RC. Prevalence and Predictors of Underweight, Stunting, and Wasting among Children Aged 5 and Under in Western Kenya. J Trop Pediatr. 2004;50(5):264.

46. Semba RD, de Pee S, Sun K, Sari M, Akhter N, Bloem MW. Effect of parental formal education on risk of child stunting in Indonesia and Bangladesh: a cross-sectional study. Lancet. 2008;371(9609):322-8.

47. Monteiro CA, Benicio MH, Konno SC, Silva AC, Lima AL, Conde WL. Causes for the decline in child under-nutrition in Brazil, 1996-2007. Rev Saude Publica. 2009:43(1):35-43.

48. Van de Poel E, Hosseinpoor AR, Jehu-Appiah C, Vega J, Speybroeck N. Malnutrition and the disproportional burden on the poor: the case of Ghana. Int J Equity Health. 2007;6:21.

49. Hong R, Hong R. Economic inequality and undernutrition in women: multilevel analysis of individual, household, and community levels in Cambodia. Food Nutr Bull. 2007;28(1):59-66.

50. Makoka D. The Impact of Maternal Education on Child Nutrition: Evidence from Malawi, Tanzania, and Zimbabwe. DHS working Papers. 2013:84.

51. Urke HB, Bull T, Mittelmark MB. Socioeconomic status and chronic child malnutrition: Wealth and maternal education matter more in the Peruvian Andes than nationally. Nutrition Res. 2011;31(10):741-7. 
52. Tessema F, Asefa M, Ayele F. Mothers' Health Services Utilization and Health Care Seeking Behavior During Infant Rearing: A Longitudinal Community Based Study, South West Ethiopia. Ethiopian J Health Development. 2002;16:51-8.

53. Assefa T, Belachew T, Ayalew T, Deribew A. Mothers' Health Care Seeking Behavior For Childhood IIInesses In Derra District, Northshoa Zone, Oromia Regional State, Ethiopia. Ethiopian J Health Development. 2008;18(3):90-3.

54. Moestue H, Huttly S. Adult education and child nutrition: the role of family and community. J Epidemiol Community Health. 2008;62(2):153-9.

55. Najnin N, Bennett CM, Luby SP. Inequalities in Care-seeking for Febrile Illness of Under-five Children in Urban Dhaka, Bangladesh. J Health Population Nutrition. 2011;29(5):523-31.

56. Nelson M. Childhood nutrition and poverty. Proc Nutr Soc. 2000;59(2):307-15.

57. Hong R, Banta JE, Betancourt JA. Relationship between household wealth inequality and chronic childhood under-nutrition in Bangladesh. Int J Equity Health. 2006:5:15.

58. Hong R, Mishra V. Effect of wealth inequality on chronic under-nutrition in Cambodian children. J Health Popul Nutr. 2006;24(1):89-99.

59. Hong R. Effect of economic inequality on chronic childhood undernutrition in Ghana. Public Health Nutr. 2007;10(4):371-8.

60. Taruvinga A, Muchenje $V$, Mushunje A: Determinants of rural household dietary diversity: The case of Amatole and Nyandeni districts, South Africa. International Journal of Development and Sustainability. 2013;2(4):1-15.

61. Doan D. Does income growth improve diet diversity in China?Selected Paper prepared for presentation at the 58 the AARES Annual Conference, Port Macquarie, New South Wales. 2014.

62. Central Statistical Agency [Ethiopia]: Ethiopia Mini Demographic and Health Survey 2014. 2014. p. 56-58. Available at http://www.unicef.org/ethiopia/ Mini_DHS_2014_Final_Report.pdf. Accessed 20 Sept 2015.

63. Masibo PK, Makoka D. Trends and determinants of undernutrition among young Kenyan children: Kenya Demographic and Health Survey; 1993, 1998, 2003 and 2008-2009. Public Health Nutr. 2012;15(9):1715-27.

64. Prendergast A, Kelly P. Enteropathies in the developing world: neglected effects on global health. Am J Trop Med Hyg. 2012;86(5):756-63.

65. Lin A, Arnold BF, Afreen S, Goto R, Huda TM, Haque R, Raqib R, Unicomb L, Ahmed T, Colford JM Jr., et al. Household environmental conditions are associated with enteropathy and impaired growth in rural Bangladesh. Am J Trop Med Hyg. 2013;89(1):130-7.

66. Spears D. How Much International Variation in Child Height Can Sanitation Explain? Policy Research Working Paper 6351.World Bank. 2013.

67. Rutstein SO. Effects of preceding birth intervals on neonatal, infant and under-five years mortality and nutritional status in developing countries: evidence from the demographic and health surveys. Int J Gynaecology Obstetrics. 2005;89 Suppl 1:S7-24.

68. Gribble JN, Murray NJ, Menott EP. Reconsidering childhood undernutrition: can birth spacing make a difference? An analysis of the 2002-2003 El Salvador National Family Health Survey. Matern Child Nutr. 2008;5(1):49-63.

69. Ikeda N, Irie $Y$, Shibuya K. Determinants of reduced child stunting in Cambodia: analysis of pooled data from three Demographic and Health Surveys. Bull World Health Organ. 2013;91:341-9.

70. Dewey KG, Cohen RJ. Does birth spacing affect maternal or child nutritional status? A systematic literature review. Maternal Child Nutrition. 2007;3:151-73.

71. Felisbino-Mendes M, Villamor E, Velasquez-Melendez G. Association of maternal and child nutritional status in Brazil: a population based crosssectional study. PLoS One. 2014;24(9):87486.

\section{Submit your next manuscript to BioMed Central and we will help you at every step:}

- We accept pre-submission inquiries

- Our selector tool helps you to find the most relevant journal

- We provide round the clock customer support

- Convenient online submission

- Thorough peer review

- Inclusion in PubMed and all major indexing services

- Maximum visibility for your research

Submit your manuscript at www.biomedcentral.com/submit 